\title{
THE REPRODUCTIVE CYCLE IN MALE NOCTULE BATS, NYCTALUS NOCTULA
}

\author{
P. A. RACEY* \\ Unit of Reproductive Biology, University of Liverpool, \\ P.O. Box 147, Liverpool L69 3BX
}

(Received 16th April 1974)

\begin{abstract}
Summary. Spermatogenesis took place in noctule bats during summer; spermatozoa were released from the testis in August and September, and the testes then involuted. Although no more spermatozoa were produced, they continued to be stored in the cauda epididymidis for the duration of winter.

The testosterone content of the testes rose with the progress of spermatogenesis from $10 \mathrm{ng} / \mathrm{pair}$ in May to $847 \mathrm{ng} / \mathrm{pair}$ in August. The concentration of the hormone in the blood plasma paralleled this increase, rising from $4.7 \mathrm{ng} / \mathrm{ml}$ to $134 \mathrm{ng} / \mathrm{ml}$ over the same period. Testosterone levels were maintained during autumn, when most mating took place, but decreased during the subsequent winter period of sperm storage. The weights of the accessory glands and their fructose content were maintained over this period.

It appears that the maintenance of active accessory glands of reproduction and of fertile spermatozoa in the epididymis has a comparatively low androgen requirement in noctule bats.
\end{abstract}

\section{INTRODUCTION}

Noctule bats (Nyctalus noctula) are distributed throughout Europe. They are insectivorous, roost mainly in holes in trees and hibernate there during winter in response to shortage of food and lowered environmental temperature. Males undergo spermatogenesis during summer, and mating is initiated in autumn (Sluiter \& Van Heerdt, 1966) but may occur throughout winter (Racey, 1972a). Females are capable of storing fertile spermatozoa in the uterus throughout winter and do not ovulate and become pregnant until spring (Racey, 1973). By delaying the time of mating and by artificial insemination, it has recently been possible to demonstrate that spermatozoa also retain their fertilizing capacity after storage in the cauda epididymidis for up to 7 months (Racey, 1972a, 1973). The main features of the reproductive cycle of noctule bats are summarized in Text-fig. 1. It can be seen that the period of sperm storage and observed libido in males coincides to some extent with hibernation, but is clearly separated from the period of spermatogenesis.

* Present address: Department of Zoology, University of Aberdeen, Aberdeen AB9 2TN. 


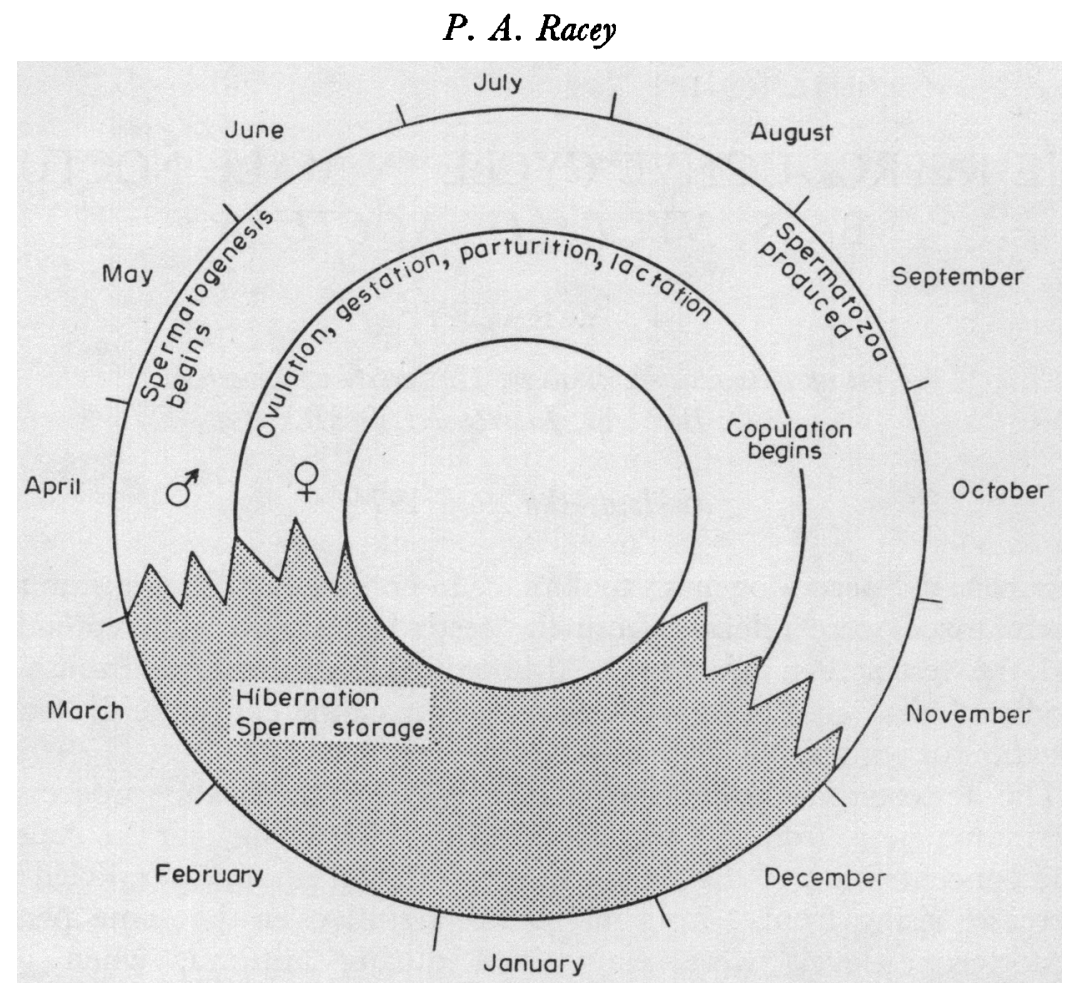

TEXT-FIG. 1. Schematic representation of the annual reproductive cycle of noctule bats.

It was, therefore, of interest to determine the sequential changes in androgen levels in these bats.

\section{MATERIALS AND METHODS}

The forty-five bats used in this study consisted of all the males from a laboratory breeding colony and, with one exception, they had been in captivity for periods ranging from 6 months to 4 years. All were adult, and fifteen were born in captivity. In order to maintain constant conditions, no bat was given the opportunity to mate during the present study. Bats were normally maintained in cages in an open 'lean-to', so they were exposed to fluctuations in external temperature and photoperiod. They were fed daily during summer and twice weekly during winter (Kleiman \& Racey, 1969; Racey, 1970). Ten bats were transferred to a cold room $\left(7\right.$ to $8^{\circ} \mathrm{C}$ ) on 16 th October 1971, and were maintained there without food until they were killed, at intervals during winter. Bats maintained in the animal house ate most of the food offered and hibernated intermittently during winter, whereas those in the cold room hibernated continuously apart from occasional spontaneous arousals. Two to six animals were killed each month (Table 1). They were anaesthetized with ether, the thorax was opened, the pulmonary artery severed and the bats were exsanguinated by draining blood from the thorax. The pituitary gland was immediately dissected, weighed and frozen with an aerosol spray (Electrolube Ltd, Slough, England) before being deep-frozen at $-20^{\circ} \mathrm{C}$. Testes, epididymides (divided 
arbitrarily into head and tail at the narrowest point), adrenals, thyroid and Cowper's glands, together with the complex of accessory organs at the base of the bladder and the interscapular brown fat were dissected and weighed. A piece of one testis was taken for histology and the remaining testis tissue was frozen. Of the remaining paired organs, the left was fixed in Bouin's fluid and the right, together with the accessory complex and the interscapular brown fat, was frozen. Both thyroid glands were fixed.

Testosterone was extracted from the testes, pooled adrenal glands and brown fat by the method of Mann, Rowson, Short \& Skinner (1967), incorporating thin-layer chromatography using silica gel, and from the blood plasma by the method of Rowe \& co-authors (1974). The recovery rate in tissue extractions was $58 \pm 2 \%$, and $89 \pm 1 \%$ in extractions of plasma, and the results were corrected for these losses. The adrenal glands were divided into four groups for the purposes of assay. Those obtained (a) from animals maintained during winter (October to March) in the cold room; (b) from those maintained during

Table 1. Number of noctule bats used in the study of seasonal changes

\begin{tabular}{l|c|c}
\hline \multirow{2}{*}{ Date of death } & \multicolumn{2}{|c}{ Environment } \\
\cline { 2 - 3 } & Animal house & Cold room \\
\hline July, 1971 & 2 & - \\
August & 2 & $=$ \\
September & 3 & - \\
October & 3 & 2 \\
November & 3 & 3 \\
December & 3 & 2 \\
February, 1972 & 2 & 3 \\
March & 3 & - \\
May & 3 & - \\
June & 3 & - \\
\hline
\end{tabular}

winter in the animal house; (c) from animals killed during May and June; (d) from animals killed during July, August and September.

Testosterone was determined by the radioimmunoassay method described by Rowe et al. (1974). The antibody was raised to testosterone linked through the 3 -keto group to bovine serum albumin. It showed a $27 \%$ cross-reaction with dihydrotestosterone but less than $0.1 \%$ with any other steroid tested. The assay is based on the separation of free and bound testosterone using dextran-coated charcoal.

The fructose content of the accessory complex was determined by a semimicro adaptation of the method used by Lindner \& Mann (1960). After grinding the glands with sand and $80 \%$ ethanol and centrifuging, the supernatant was evaporated to dryness. The residue was taken up in $300 \mu \mathrm{l}$ water and the method of Lindner \& Mann (1960) followed, using proportionate quantities. This gave sufficient final volume to fill the microcuvette of a Cecil CE303 grating spectrophotometer.

The frozen epididymides were homogenized, the homogenate was made up to 
25,50 or $100 \mathrm{ml}$ depending on sperm density, and the numbers of spermatozoa were counted using a haemocytometer.

A piece of testis, together with one adrenal and one Cowper's gland, and both thyroid glands from each animal were embedded in paraffin wax, sectioned at $5 \mu \mathrm{m}$, and stained with haematoxylin and eosin. Sections of one thyroid gland were subjected to the periodic acid-Schiff procedure and the area of colloid was measured by a Quantimet scanning microscope.

Two diameters were measured in cross-sections in each of five seminiferous tubules in each individual. Two widths of the adrenal cortex were measured in the widest cross-section of the gland, and measurements were also made of the height of the epididymal epithelium.

Eight noctules, all of which were born in 1970, and achieved sexual maturity in 1971, were maintained in a cold room at about $7^{\circ} \mathrm{C}$ from October 1971 until the end of January 1972 when they were aroused from hibernation. Four were castrated under halothane/oxygen anaesthesia and all were then maintained at a temperature of 20 to $25^{\circ} \mathrm{C}$, with a 6-hr photoperiod, and with food freely available. Two castrated and two control animals were killed after 1 week and the remainder after 2 weeks. Weights of testes and accessory complexes were recorded.

\section{RESULTS}

Body weight

Changes in body weight are illustrated in Text-fig. 2. They showed a steep rise before hibernation, and declined slowly during the following winter and summer.

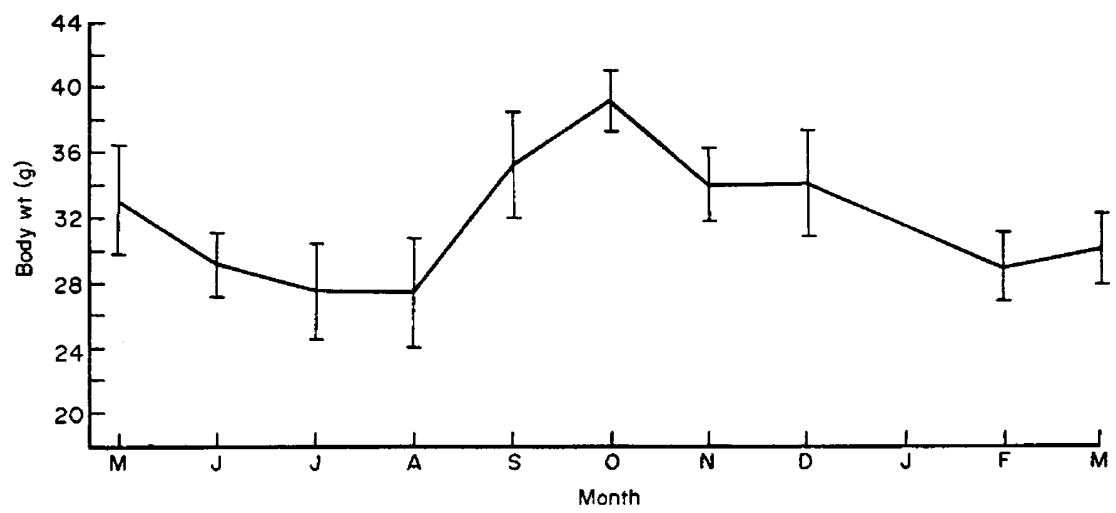

TEXT-FIG. 2. Annual changes in the mean body weight of male noctule bats. Vertical bars represent the S.E.M.

Testis

Changes in the weight of the testes and the diameter of the seminiferous tubules are shown in Text-fig. 3. During winter, the tubules of the testis consist of a single layer of darkly staining shrunken Sertoli cell nuclei and occasional large spermatogonia with prominent nucleoli. The first changes in the testis 
are seen during March and consist of an increase in the volume of Sertoli cell cytoplasm. Spermatogonia do not divide, however, until May and June. Spermatogenesis proceeds during summer and is accompanied by a thirteenfold increase in the mean weight of the testes. Spermatozoa are released from the seminiferous tubules in August and September, leaving them denuded of their contents. As the testes shrink during October, the epididymides, especially the caudae, increase in size.

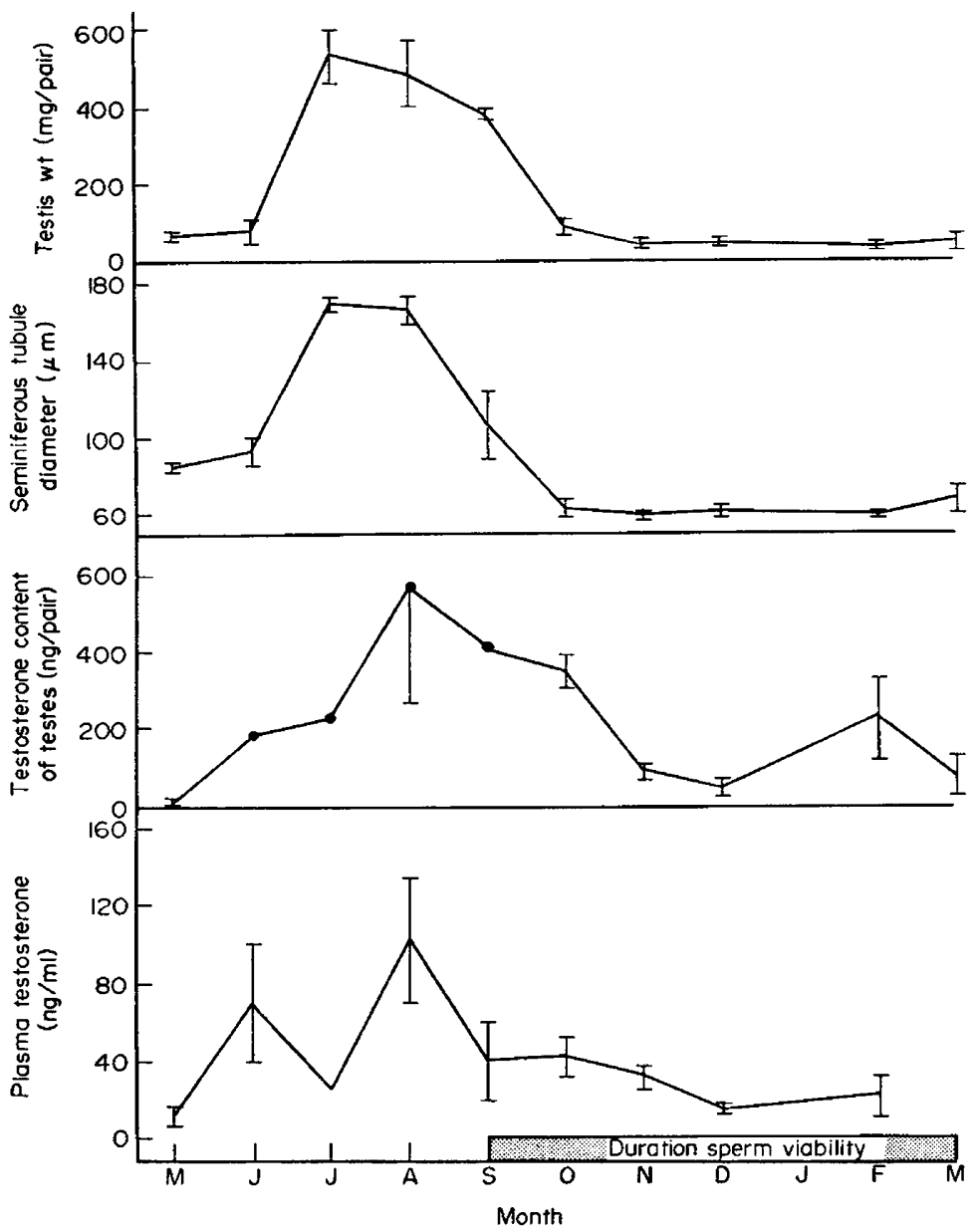

Text-Fig. 3. Seasonal changes in the mean weight of the testes, diameter of the seminiferous tubules, testosterone content of the testes, and testosterone concentration in the blood plasma of noctule bats. Vertical bars represent the S.E.M.

The Leydig cells are never abundant, and no clear changes are apparent in the relative volume of their cytoplasm. Their nuclei are spherical, about $17 \mu \mathrm{m}$ in diameter, and show little change throughout the year.

The range for individual values of testosterone from animals adapted to captivity ranged from $10 \mathrm{ng} /$ pair testes (May) to $847 \mathrm{ng} /$ pair (August) and plasma values ranged from $4 \cdot 7 \mathrm{ng} / \mathrm{ml}$ (May) to $134 \mathrm{ng} / \mathrm{ml}$ (August) (Table 2). 
The highest values recorded were $3240 \mathrm{ng} /$ pair of testes and $288 \mathrm{ng} / \mathrm{ml}$ plasma in a single individual held in captivity for only $36 \mathrm{hr}$ before death. Because this individual was not adapted to captivity, these data were excluded from Textfig. 3.

Changes in the content of testosterone in the testes and the concentration in the plasma showed that there were peaks in August after the testicular weight and seminiferous tubule diameter became reduced. The levels of testosterone then declined progressively to reach the lowest winter level in December $(53 \pm 23 \mathrm{ng})$. A transitory increase in the testis content of testosterone was observed in February and was accompanied by a slight rise in plasma levels.

The content of testosterone in the testes correlated well with the concentration in the blood plasma throughout the year $(r=0.96 ; P<0.001)$ but not with the weight of the accessory complex $(r=0 \cdot 15)$.

Table 2. Testosterone in the testes and blood plasma of noctule bats

\begin{tabular}{|c|c|c|c|}
\hline Month & Maintenance of bats & $\begin{array}{c}\text { Testicular } \\
\text { testosterone content } \\
\text { (ng/pair) }\end{array}$ & $\begin{array}{l}\text { Plasma testosterone } \\
\text { concentration } \\
(\mathrm{ng} / \mathrm{ml})\end{array}$ \\
\hline $\begin{array}{l}\text { July } \\
\text { July } \\
\text { August } \\
\text { August } \\
\text { September } \\
\text { October } \\
\text { October } \\
\text { November } \\
\text { November } \\
\text { November } \\
\text { December } \\
\text { December } \\
\text { December } \\
\text { February } \\
\text { February } \\
\text { February } \\
\text { March } \\
\text { March } \\
\text { March } \\
\text { May } \\
\text { May } \\
\text { May } \\
\text { June }\end{array}$ & $\begin{array}{l}\text { Animal house } \\
\text { Killed } 36 \text { hr after capture } \\
\text { Animal house } \\
\text { Animal house } \\
\text { Animal house } \\
\text { Animal house } \\
\text { Animal house } \\
\text { Animal house } \\
\text { Animal house } \\
\text { Cold room } \\
\text { Animal house } \\
\text { Animal house } \\
\text { Cold room } \\
\text { Animal house } \\
\text { Animal house } \\
\text { Cold room } \\
\text { Cold room } \\
\text { Cold room } \\
\text { Animal house } \\
\text { Animal house } \\
\text { Animal house } \\
\text { Animal house } \\
\text { Animal house }\end{array}$ & $\begin{array}{r}220 \\
3240 \\
263 \\
847 \\
414 \\
390 \\
316 \\
59 \\
93 \\
110 \\
99 \\
40 \\
21 \\
297 \\
372 \\
15 \\
185 \\
51 \\
14 \\
12 \\
12 \\
10 \\
184\end{array}$ & $\begin{array}{r}23 \\
288 \\
70 \\
134 \\
45 \\
60 \\
40 \\
22 \\
45 \\
15 \\
17 \\
19 \\
13 \\
29 \\
50 \\
4 \\
- \\
- \\
21 \\
13 \\
4 \cdot 7 \\
73\end{array}$ \\
\hline
\end{tabular}

\section{Epididymides}

Changes in weight and sperm content are shown in Text-fig. 4. The lowest weights of caput and cauda epididymidis were recorded in June, slight growth occurred during the following month, and maximum weights occurred during September, coinciding with maximum sperm content. The weight of the caput epididymidis fell progressively throughout winter and few residual spermatozoa were recorded there during November, but the weight of the cauda epididymidis was maintained throughout winter. Although the urine first voided by males on arousal from hibernation was often clouded with spermatozoa, sufficient spermatozoa were retained throughout winter to render the males euspermic. 


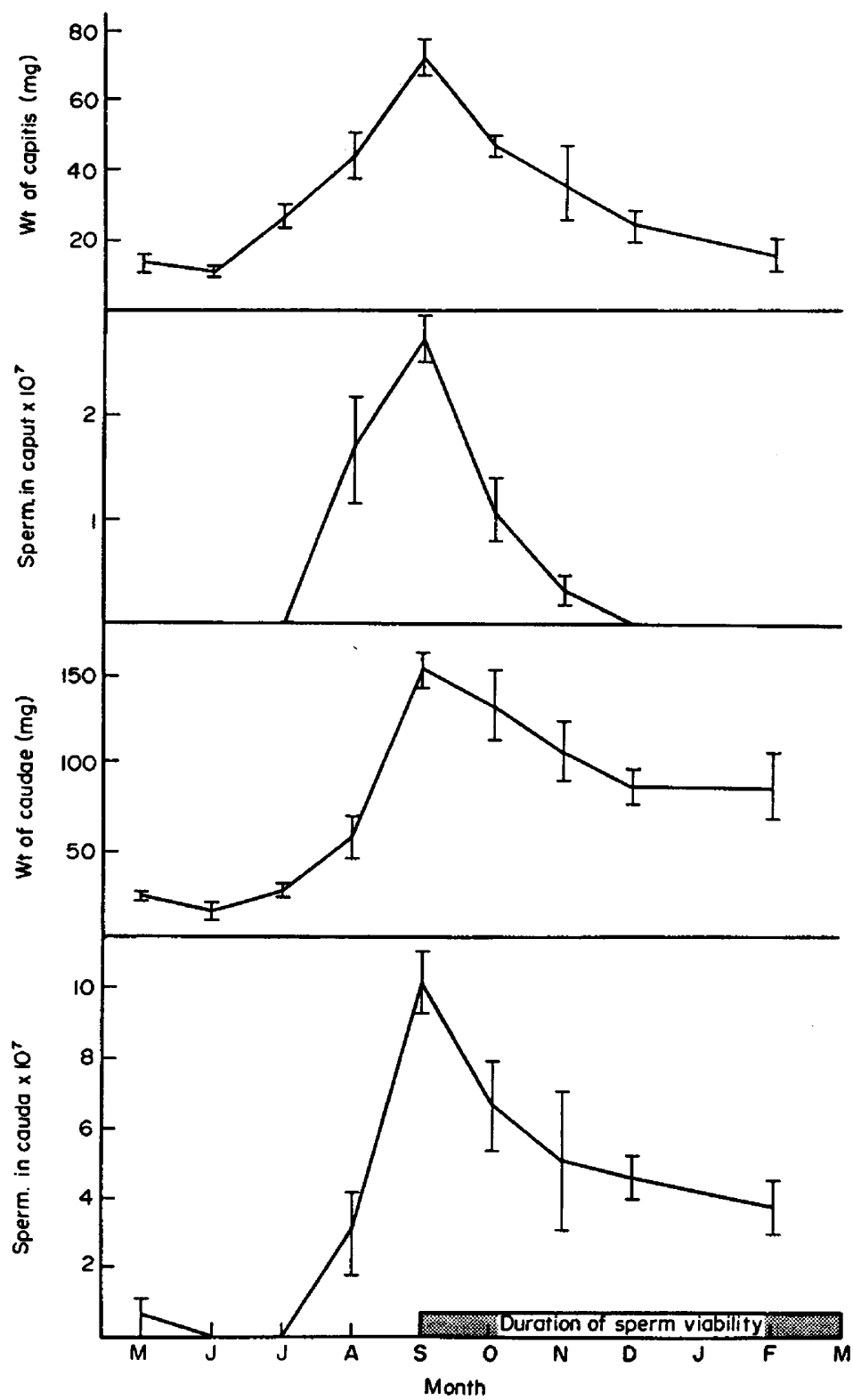

TexT-Fro. 4. Seasonal changes in the mean weight and sperm content of the caput and cauda epididymidis in noctule bats. Vertical bars represent the S.E.M.

During March, epididymides were macerated and spermatozoa were artificially inseminated into females and their fertilizing ability was demonstrated (Racey, 1973).

\section{Accessory glands}

The complex of accessory glands at the base of the bladder consists of a 
median prostate, paired ampullary glands, and paired coagulating glands (Racey \& Tam, 1974). It was difficult to separate these components accurately, so they were treated as a whole referred to as the accessory complex.

Both the accessory complex and Cowper's glands increased in weight during the summer to reach a peak in September (Text-fig. 5) and both showed only

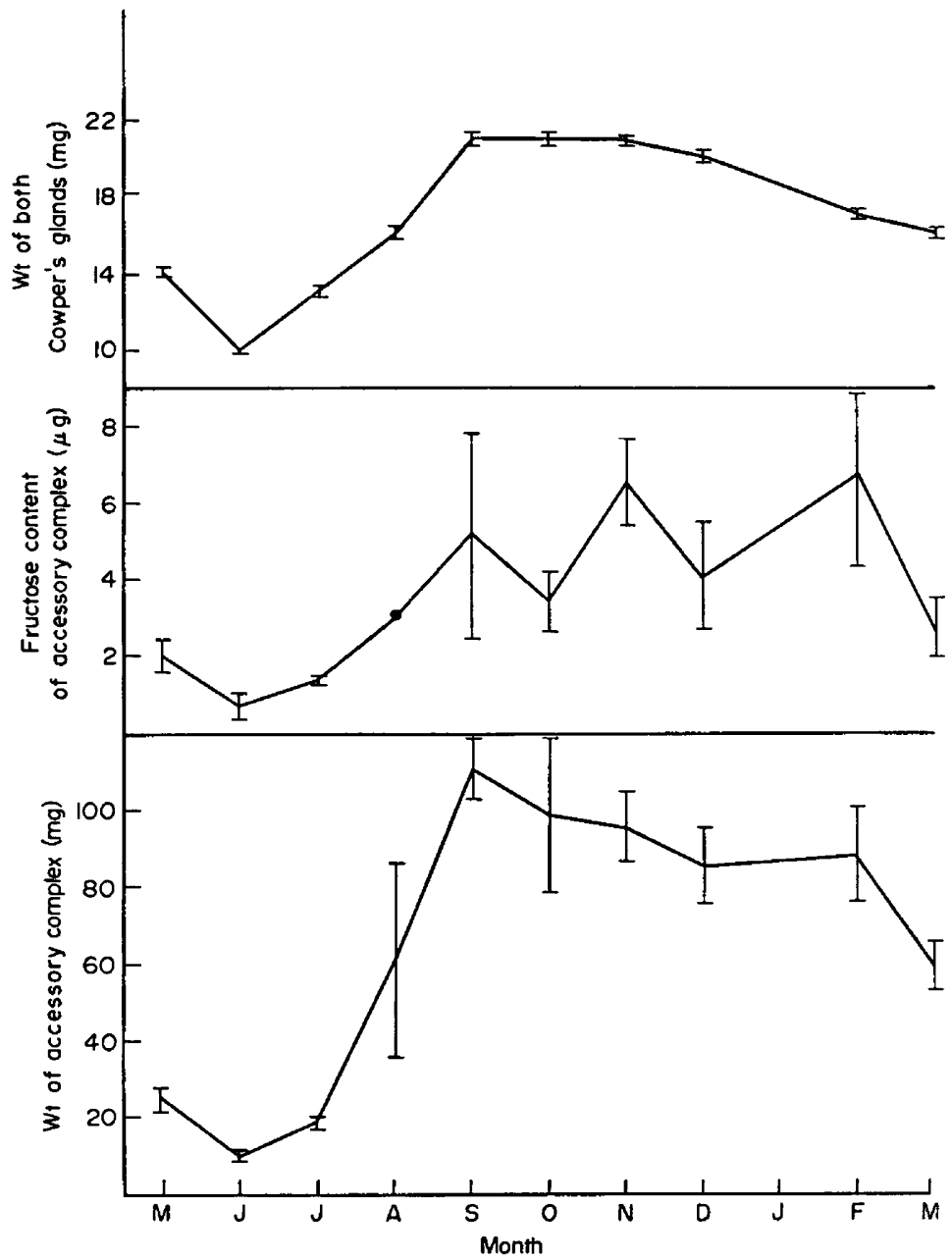

TEXT-FIG. 5. Seasonal changes in the mean weight of the Cowper's glands, the accessory complex and its fructose content in noctule bats. Vertical bars represent the S.E.M.

slight involution during winter. The fructose content of the accessory complex was more variable, but also increased from the June minimum to maintain high values during winter. It was not correlated with the content of testosterone in the testes $(r=0 \cdot 11)$.

The accessory complex of males which had been castrated and aroused from hibernation decreased in weight in contrast to those of intact males, also aroused from hibernation, which increased in weight (Text-fig. 6). The mean weight 
of testes removed at castration was $33.0 \mathrm{mg} / \mathrm{pair}(\mathrm{N}=4)$. The mean weight of those removed from two noctules, serving as controls, 1 week after arousal was $38.5 \mathrm{mg} /$ pair, and of those removed from a further two controls 2 weeks after arousal was $59.7 \mathrm{mg} /$ pair. Increased temperature and food supply thus resulted in the initiation of spermatogenesis in the control bats, and this was confirmed histologically.

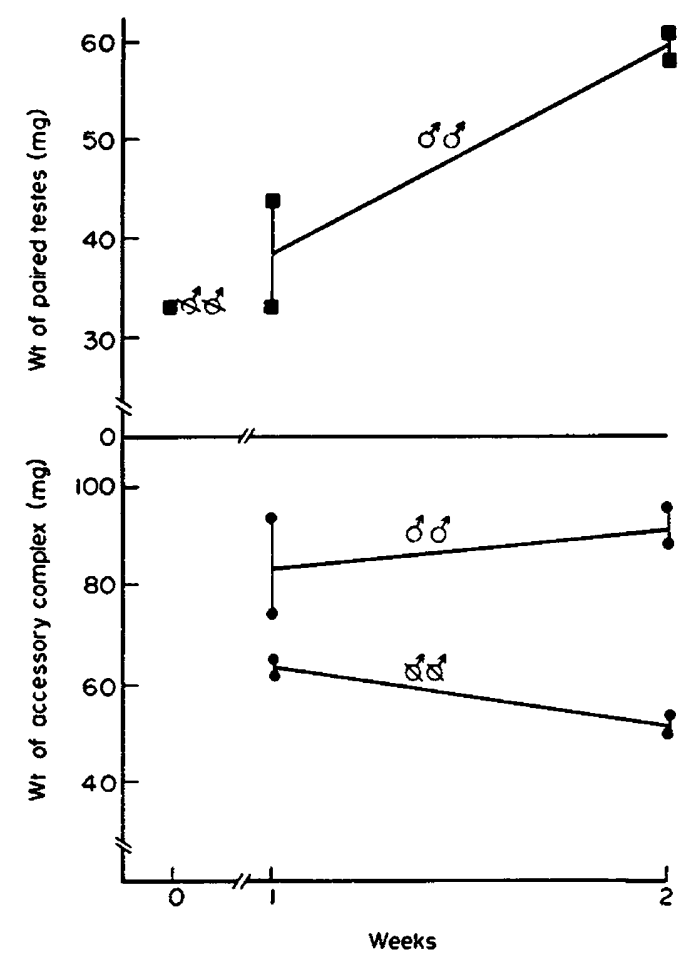

TeXr-Fig. 6. The effect of castration and arousal, in mid-January, on the weight of the accessory complex in noctule bats.

\section{Pituitary}

The pituitary increased in weight slowly during winter and was heaviest in early summer (Text-fig. 7). A significant weight loss then occurred until a nadir was reached in September (May versus September: $P<0.01$ ).

\section{Adrenal glands}

Changes in the weight of the adrenal glands followed those of the pituitary (Text-fig. 7). An increase occurred during winter to a peak in early summer, and this was followed by a significant fall in weight throughout summer (May versus October: $P<0 \cdot 01$ ). Variations in the width of the adrenal cortex did not correspond, however, to these changes in weight and no testosterone was detected in any of the pooled samples of adrenal glands. 
Thyroid glands

There were no significant changes in the weight of the thyroid glands and the percentage of thyroid colloid during the year (Text-fig. 7). The percentage of colloid did, however, rise during late summer and autumn and was highest in November and December, when the bats were least active.

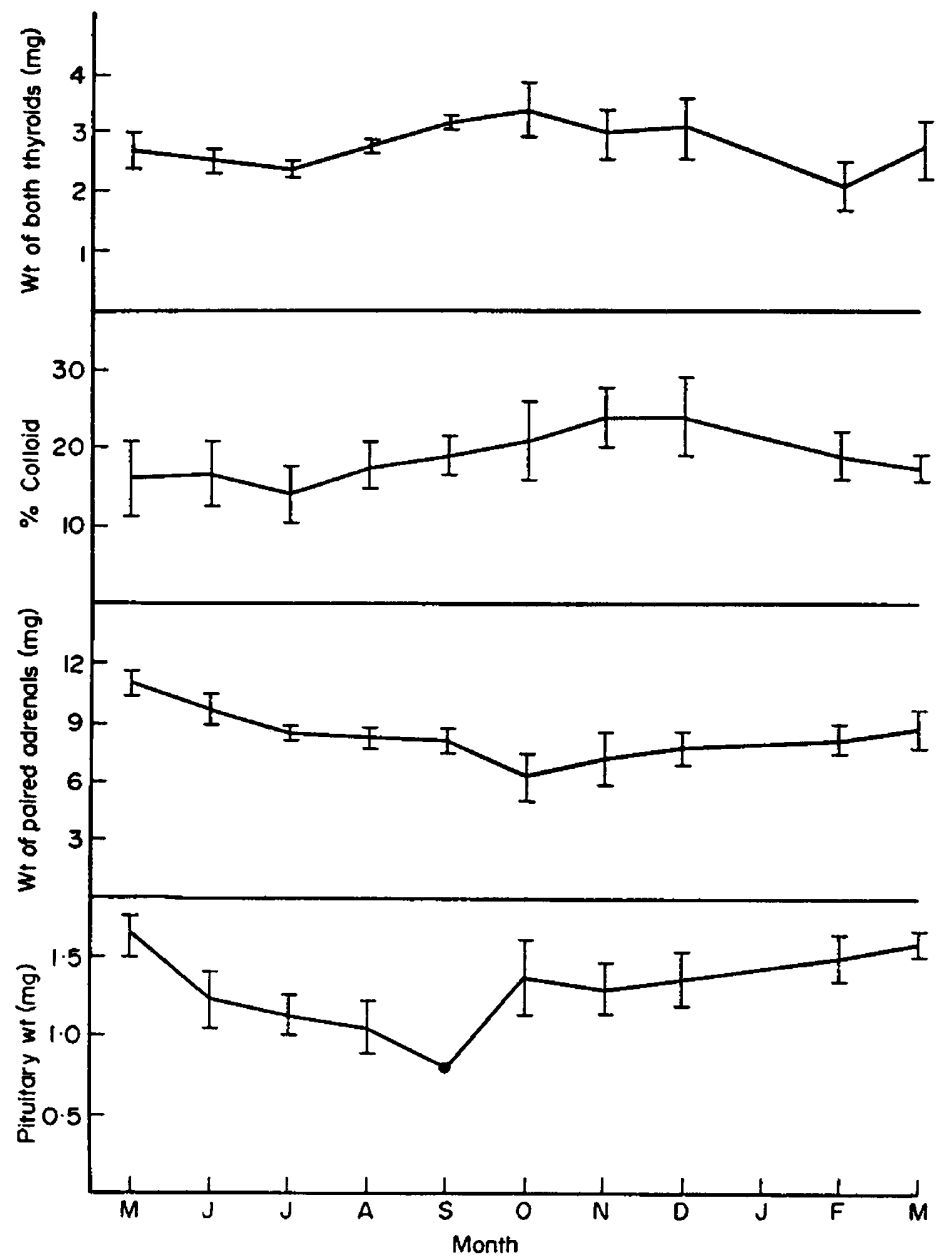

TEXT-FIG. 7. Seasonal changes in the mean weight of pituitary, adrenal and thyroid glands, and in the mean area of thyroid colloid of noctule bats. Vertical bars represent the S.E.M.

\section{Brown fat}

Testosterone was not detected in any sample of brown fat.

\section{Behaviour}

In male noctules, the period of spermatogenesis is characterized by increased aggressiveness. When males are caged together during this time, one of them will assume dominance, drive others from the nest box, and signify his occupation by prolonged high-pitched vocalization which is sometimes answered by his 
cagemates. He will repel intruders but may be ousted if he loses one of the occasional but vicious fights.

Wild adult males were found during the present study cohabiting in a tree hole during July. They revealed themselves by the same prolonged high-pitched vocalization which characterizes captive bats, and were eventually caught in mist nets.

During winter, males caged together showed no signs of aggressive behaviour. Those housed in the animal house hibernated intermittently from November to March, and the depth of hibernation depended on the environmental temperature. Except during very cold weather, they awoke to eat the food placed in their cages. Whenever they were inspected, the animals housed in the cold room were always found to be in deep hibernation.
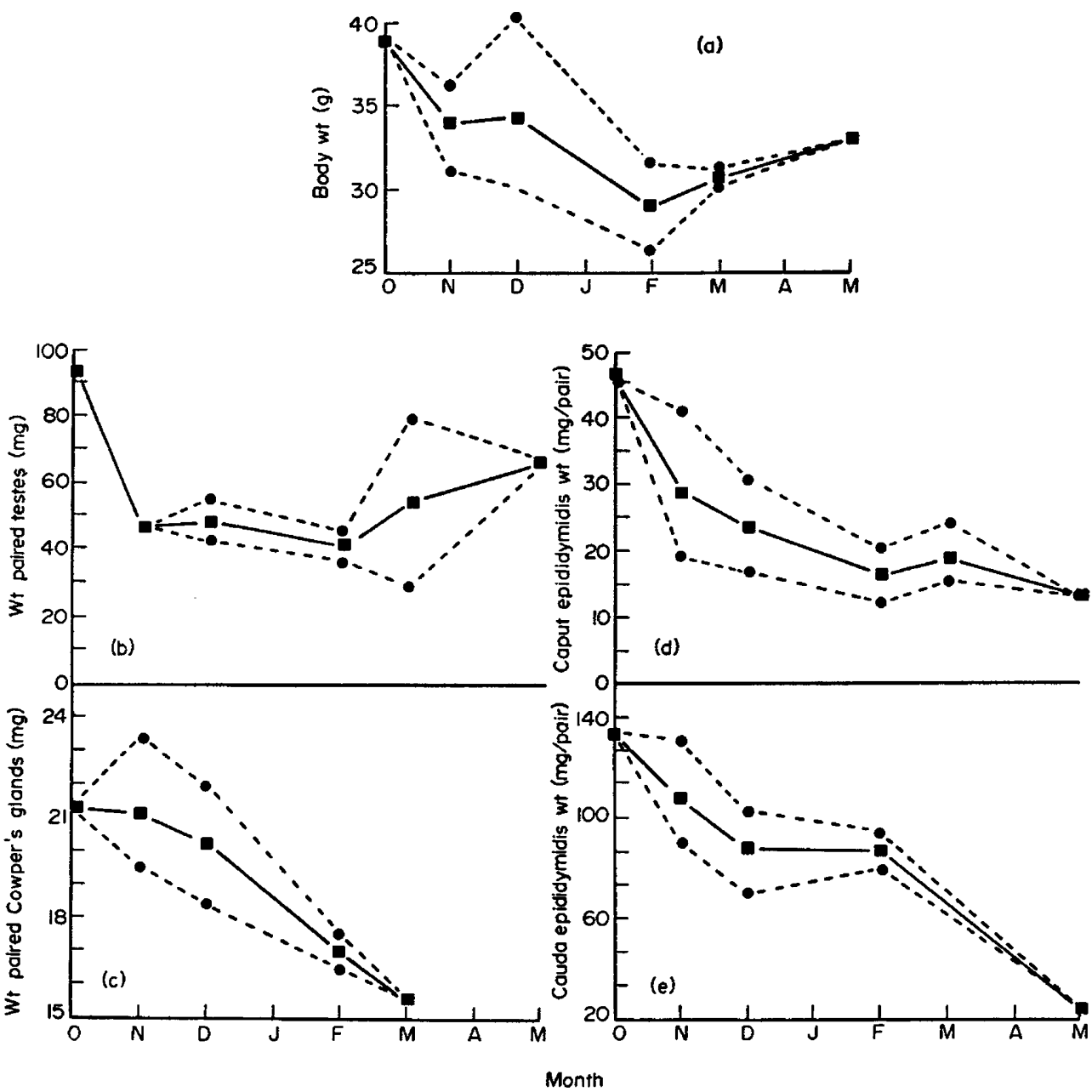

Text-Fig. 8. A comparison between (a) the mean weight of noctule bats and ( $b$ to $e$ ) the mean weight of some of their reproductive organs during continuous and intermittent hibernation. The heavy solid line represents the overall mean. The mean for bats hibernating continuously is represented by the broken line above the overall mean, and the mean for bats hibernating intermittently by the broken line below the overall mean. 
Differences between continuously and intermittently hibernating bats

All data obtained from animals hibernating continuously in the cold room during winter and those hibernating intermittently in the animal house were compared. The mean weight of bats maintained in the animal house, together with their testes, accessory complex and Cowper's glands were invariably lower than comparable weights from animals maintained in the cold room (Text-fig. 8).

\section{DISCUSSION}

In most seasonally breeding mammals, the endocrine and exocrine functions of the testis are closely synchronized (Short \& Mann, 1966). Hibernating bats are exceptional in that they store spermatozoa, have active accessory glands, and mate for many months after the seminiferous tubules have involuted, suggesting that the Leydig cells continue to secrete testosterone. Such bats provide a unique opportunity to investigate the endocrine function of the testis in isolation from its exocrine function. In captive noctule bats, the highest levels of testicular and plasma testosterone are associated with spermatogenesis, although this androgen continues to be found in appreciable quantities during the autumn mating season. These results confirm and extend those obtained by Racey \& Tam (1974) in the closely related pipistrelle bat, Pipistrellus pipistrellus, in which the highest percentage conversion of pregnenolone to androstenedione and testosterone was found to coincide with spermatogenesis. With the onset of hibernation in November and December, testosterone levels declined in the noctule, and relatively low levels were found throughout winter. In-vitro androgenesis in the pipistrelle was also lowest during winter.

The fact that the highest levels of testosterone were recorded in a recently caught noctule in the present study raises the question of whether captivity depresses androgenesis. The fertilizing capacity of epididymal spermatozoa after prolonged storage was established in the bats which formed part of this study (Racey, 1972a, 1973) so that correlations established by the present work between the relative level of testosterone in the testis and the fertility of spermatozoa stored in the epididymis are probably valid.

Both in-vitro androgenesis in the pipistrelle and the testicular content of testosterone in the noctule showed a transitory increase during February, which is difficult to explain. It is possible to induce female pipistrelles to ovulate by premature arousal from hibernation in February, suggesting that the new cycle of gonadotrophin secretion may begin at that time (Racey, 1972b). This may also be the case in males.

In homeothermic animals, the weight of the accessory glands of reproduction is related to the concentration of circulating androgens (Lindner \& Mann, 1960). In hibernating bats, this relationship is complicated by the fact that involution of the accessory glands in response to falling androgen levels may be inhibited by the torpor of hibernation. The accessory complex was thus unaffected in pipistrelle bats that were castrated and returned to hibernation (Racey \& Tam, 1974). In the present work, the fact that the mean body weight of noctules and the mean weight of their testes and accessory glands of reproduction were higher in bats which hibernated continuously than in those which 
hibernated intermittently (Text-fig. 8 ) provides additional evidence that the torpor of continuous hibernation slowed the regressive changes which occurred in more active animals. Abrupt withdrawal of androgen by castration followed by arousal from hibernation, however, caused involution of the accessory complex in noctules and pipistrelles. Such involution is not the result of arousal alone since the accessory complex of intact animals aroused at the same time involuted more slowly in pipistrelles (Racey \& Tam, 1974) and not at all in noctules.

Seasonal changes in the content of testosterone in the testes have been determined in roe and red deer (Short \& Mann, 1966; Lincoln, 1971), hyrax (Millar $\&$ Glover, 1973) and hares (Lincoln, 1974). In these species, as in bats, the highest levels of testosterone are associated with spermatogenesis and the rut. Studies on the civet cat (Paguma larvata) (W. H. Tam, H. W. Tsui, B. Lofts \& J. G. Phillips, unpublished results) and the pipistrelle bat (Racey \& Tam, 1974) reveal that in-vitro androgenesis is also highest during spermatogenesis. Testosterone was found in bat testes throughout winter, though in reduced quantities. Previous observations on our laboratory colony of noctules have shown that copulation occurs most frequently in September and October (Kleiman \& Racey, 1969) but that copulations occurring throughout winter are also successful (Racey, 1972a).

The results obtained in the present work on male noctules and also from that on pipistrelles (Racey \& Tam, 1974) suggest that, of the several androgendependent processes associated with reproduction in male bats, the survival of spermatozoa in the cauda epididymidis and the maintenance of libido during winter have a comparatively low androgen requirement. Observations on several mammalian species confirm that copulatory behaviour, once established, requires little androgen for its maintenance (see Lincoln, Guinness \& Short, 1972). The abolition of fertility in male rats by much lower levels of antiandrogen than those required to abolish other androgen-dependent functions also suggests that the maintenance of viable spermatozoa in the cauda epididymidis has a comparatively low androgen requirement (Prasad, Rajalakshmi \& Reddy, 1972).

\section{ACKNOWLEDGMENTS}

I should like to thank Dr T. D. Glover for his interest and encouragement in this work, Mr P. H. Rowe for providing the antibody used in the radioimmunoassay, Miss Thelma Brown for typing the manuscript, and Huntingdon Research Centre for Quantimet Scanning of the thyroid sections.

\section{REFERENGES}

KLEIMAN, D. G. \& RaceY, P. A. (1969) Observations on noctule bats Nyctalus noctula breeding in captivity. Lynx, 10, 65.

Lincoln, G. A. (1971) The seasonal reproductive changes in the red deer stag (Cervus elaphus). F. Zool., Lond. 163, 105.

Lincol, , G. A. (1974) Reproduction and "March-madness" in the brown hare Lepus europaeus. F. Zool., Lond. 174, (in press).

Lincoln, G. A., Guinness, F. \& Short, R. V. (1972) The way in which testosterone controls the social and sexual behaviour of the red deer stag (Cervus elaphus). Horm. E Behav. 3, 375. 
LiNDNER, H. R. \& MANN, T. (1960) Relationship between the content of androgenic steroids in the testes and the secretory activity of the seminal vesicles in the bull. F. Endocr. 21, 341 .

ManN, T., Rowson, L. E. A., Short, R. V. \& Skinner, J. D. (1967) The relationship between nutrition and androgenic activity in pubescent twin calves, and the effect of orchitis. F. Endocr. 38, 455.

Mrllar, R. P. \& Glover, T. D. (1973) Regulation of seasonal sexual activity in an ascrotal mammal, the rock hyrax (Procavia capensis). 7. Reprod. Fert., Suppl. 19, 203.

Prasad, M. R. N., Rajalakshmi, M. \& Reddy, P. R. K. (1972) Action of cyproterone acetate on male reproductive functions. Hormones and antagonists. Gynecol. Invest. 2, 202.

RACEY, P. A. (1970) The breeding, care and management of vespertilionid bats in the laboratory. Lab. Anim. 4, 171.

RACEY, P. A. (1972a) Viability of bat spermatozoa after prolonged storage in the epididymis. F. Reprod. Fert. 28, 309.

RACEY, P. A. (1972b) Aspects of reproduction in some heterothermic bats. Ph.D. thesis, University of London.

RACEX, P. A. (1973) The viability of spermatozoa after prolonged storage by male and female European bats. Period. Biol. 75, 201.

RACEx, P. A. \& TAM, W. H. (1974) The reproductive cycle in the male pipistrelle bat, Pipistrellus pipistrellus. F. Zool., Lond. 172, 101.

Rowe, P. H., Lincoln, G. A., Racey, P. A., Lehane, J., Stephenson, M. J., Shenton, J. G. \& Glover, T. D. (1974) Temporal variations of testosterone levels in the peripheral blood plasma of men. 7. Endocr. 61, 63.

SHort, R. V. \& MANN, T. (1966) The sexual cycle of a seasonally breeding mammal, the roebuck (Capreolus capreolus). F. Reprod. Fert. 12, 337.

Slutrer, J. W. \& VAN HEERdt, P. F. (1966) Seasonal habits of the noctule bat (Nyctalus noctula). Archs néerl. Zool. 16, 423. 